\title{
Carbon capacity of gray forest soils in the Chechen Republic
}

\author{
Rustam Gakaev* \\ Chechen State University named after A.A.Kadyrov, 364024, st. Sheripova, 32, Grozny, Russia
}

\begin{abstract}
Common areas of research needed to measure soil carbon include: (1) the impact of forest management, (2) the impact of climate change, and (3) the impact of increased carbon dioxide. The organic matter of the soil has a great influence on the productivity of the site due to its effect on the physical (bulk density, water retention capacity), biological (microbial populations) and chemical (cation exchange capacity) properties of soils. Recently, there have also been claims of the benefits of dead wood for forest ecosystems. However, as with all nutrients, too much carbon in the soil can have negative consequences, especially with regard to nitrogen immobilization.
\end{abstract}

\section{Introduction}

Reclamation and reforestation can capture the most carbon per hectare. However, these activities come with high upfront costs, opportunity costs of land-use change (including implications for food security), onerous commitments to sustained use, and no longer generating carbon offset revenues once carbon equilibrium is reached. Carbon equilibrium is the point at which the rate of carbon accumulation equals the rate of carbon emission, so net bonding effectively stops. Marginal land projects that use logging systems to maintain income and employment on project land after carbon equilibrium has been achieved may pose less risk. Rangeland restoration usually has a low sequestration potential per hectare, but potentially has significant environmental benefits. Although the methodologies have not yet been approved, low sequestration levels mean that these actions should be targeted at areas with the highest sequestration potential and low verification costs, resource inputs and opportunity costs. Rangeland restoration activities are also associated with onerous rangeland conservation obligations. The main attention when increasing the SOC should be directed to improving agricultural productivity and the state of land resources [1].

When considering the role of natural forests in the global carbon cycle, it is useful to consider the "color" of carbon. Gray carbon (3) is the carbon stored in fossil fuels (coal, oil and gas deposits in the lithosphere). Green carbon is carbon stored in the biosphere. We call it "green" because carbon is absorbed by plants from the atmosphere through photosynthesis, which depends on the green pigment chlorophyll found in plant leaves (4). Here we use the term green carbon to refer to carbon captured through photosynthesis and stored in natural forests. Natural forests are here defined as forests that have not been

*Corresponding author: rustam.geofak@yandex.ru 
disturbed by intensive human land use activities, including commercial logging. Brown carbon is carbon stored in industrial forests. These are forests that are harvested to obtain wood, which is used as a source of raw materials for industrial production processes. There are two types of industrial forests: 1) where the growth of trees occurs at the expense of the natural tree stock and seed fund; and 2) where the trees are planted by humans and usually consist of one tree species, which is very similar to a monoculture culture [4]. Industrial forests are a stock of organic carbon and are therefore part of the biosphere; however, we consider this carbon to be 'brown' rather than 'green' to highlight the fact that industrialized forests are a 'mixture' of green and gray carbon (5). Fossil fuels are consumed and hence gray carbon is emitted in the management of these forestry operations and associated manufacturing processes. Blue carbon refers to the inorganic carbon stored in the atmosphere and oceans. Despite the fact that the ocean contains significant reserves of marine green carbon (6), here we are interested in green carbon stored in terrestrial ecosystems and, in particular, in natural forests [5].

It was only after the United Nations Climate Change Conference in Bali in 2007 that international negotiations focused on the role of natural forests in storing carbon. The Intergovernmental Panel on Climate Change (IPCC) has identified the need for forest-based mitigation analyzes that take into account natural variability, use raw data and provide reliable baseline carbon accounts. In response, we are conducting a series of studies on carbon stocks in pristine natural forests over large geographic areas, including environmental factors at landscape and regional scales. We also look at the carbon impact of land use activities, including commercial logging. The key question we ask in our study is, "How much carbon can natural forests accumulate if they are not disturbed by intense human land-use activities?" This report summarizes the results of case studies in the forests of the Chechen Republic. At the same time, the highest technogenic and chemical pollution is typical for the central part of the republic, where the industrial centers Grozny, Argun, Gudermes are located, which are among the largest environmental pollutants [6].

\section{What is the role of forests in the carbon cycle?}

It is the biological, ecological and evolutionary aspect that distinguishes "green" carbon in natural forests from "brown" carbon in industrial forests, especially monoculture plantations. Relying on the same poetic license, we call inorganic carbon in the atmosphere (carbon dioxide) and oceans (carbonate) blue carbon. Natural forests are more resilient to climate change and disturbance than plantations because of their genetic, taxonomic and functional biodiversity [7]. This resilience includes fire recovery, pest and disease resistance and recovery, and adaptation to changes in radiation, temperature and water availability (including as a result of global climate change). Although the genetic and taxonomic makeup of forest ecosystems changes over time, natural forests will continue to absorb and store carbon as long as there is enough water and solar radiation for photosynthesis. Green carbon in natural forests is stored in more reliable stocks than in industrial forests, especially at ecological time scales. Carbon stored in industrial forests is more susceptible to losses than carbon stored in natural forests. Industrial forests, especially plantations, have reduced genetic diversity and structural complexity and therefore reduced resistance to pests, diseases and changing climatic conditions [8]. Carbon stocks in forests subject to commercial felling, and in particular in monoculture plantations, will, on average, always be significantly less ( $\sim 40-60 \%$ depending on land use intensity and forest type) than carbon stocks in natural, intact forests. forests. The rate of carbon fixation by young regenerating plantations is high, but this does not compensate for the lower carbon stocks in the younger plantations of industrial forests compared to natural forests. Carbon 
accounts for industrial forests should include carbon emissions associated with land use and associated management, transport and processing activities.

The destruction of the Chechen forest by fires began more than 300 years ago, the command of the tsarist troops destroyed forest vegetation with arson. In place of oak geosystems, transformed herbaceous rows arose, as the fires resulted in significant changes in environmental conditions. "The change in the phytoclimate alone and the changes in the soil climate going along with it can be very noticeable and lead to such changes in the soil regime, which can be completely unfavorable for the restoration of the former vegetation, in our case, beech geosystems [9]. The total overlapping of time fluctuations of extreme values of the functioning of systems and the environment has created conditions conducive to structural changes in the geosystems of the region, which were activated in the process of anthropogenic impact. Under the influence of climate xerophytic factors in the eastern and southeastern parts of the territory, the areas of small-leaved and shrub geosystems are expanding and beech and oak geosystems are being pushed back to higher levels.

Access to relevant environmental field data is critical to accurately accounting for carbon in natural forests, otherwise misleading values will be generated. Models need to be developed and calibrated to reflect the fact that the carbon dynamics of natural forests differs significantly from those of industrial forests, especially monoculture plantations. Among other things, carbon in natural forests has a longer residence time. We demonstrated this by comparing our data with forest carbon accounts calculated from two commonly used sources. In terms of the global biome, Australian forests are classified as temperate forests. The IPCC default values for temperate forests are: carbon stock $217 \mathrm{t} \mathrm{C} \mathrm{ha-1} \mathrm{of} \mathrm{total}$ carbon, $96 \mathrm{t} \mathrm{C}$ ha-1 biomass carbon and NPP $7 \mathrm{t} \mathrm{C}$ ha-1 year-1. The IPCC default values for total carbon are about one third and for biomass carbon about a quarter of the averages for eucalyptus forests in southeastern Australia and one twentieth of the eucalyptus forests with the highest carbon density in biomass. We estimate that the total carbon stock that can be stored in the 14.5 million hectares of eucalyptus forests in our study region is $9.3 \mathrm{Gt}$ (1) if not disturbed by intense human land use; applying the IPCC defaults will only give $3.1 \mathrm{Gt}$. The difference in carbon stocks between our estimates and the IPCC default values is a result of our using local data collected from natural forests not disturbed by logging. Thus, our estimates reflect the carbon capacity of natural forests. In heavily disturbed forests, current carbon stocks reflect the history of land use. The difference between the two is called the "carbon sequestration potential" - the maximum amount of carbon that can be sequestered as the forest regains its growth.

Scientifically, green carbon accounting and the protection of natural forests in all countries should be part of an integrated approach to tackling climate change. Ongoing international negotiations focus on reducing emissions from deforestation and forest degradation only in developing countries. Part of the current international negotiations on climate change includes discussions on a technical definition of key terms. "Forest degradation" should be defined to include the impacts of any human land use activity that reduces the carbon stock in the forest landscape relative to its natural carbon capacity. The definition of "forest" should also be revised to recognize the differences between the ecological characteristics of natural forests and industrial forests, especially plantations. These differences include higher biodiversity, ecosystem resilience, and carbon retention times in natural forests.

\section{Results and Discussions}

Terrestrial ecosystems, especially natural forests, play a critical role in regulating atmospheric greenhouse gases and therefore must be part of a comprehensive response to climate change. Understanding the importance of natural forests in the carbon cycle 
requires understanding how the Earth functions as a system. Since the Earth is a closed system in terms of chemical elements, the atomic components of the main greenhouse gases (water vapor, carbon dioxide and methane) are not created or destroyed. Rather, they inhabit reservoirs (also called "reserves" or "reservoirs") and move between them in the global carbon and hydrological cycles [10]. As they move between reservoirs, carbon and water change their state: water from liquid turns into gas or ice; and carbon from inorganic gases in the atmosphere to organic compounds in living and dead organisms on land and in the sea, to inorganic substances in the oceans and the earth's crust [14]. A simplified diagram of the global carbon cycle is shown in Figure 1. Estimates of global carbon stocks and fluxes are rough estimates due to lack of data. The annual uptake of carbon (in the form of carbon dioxide) by plants (through photosynthesis) from the atmosphere to plants and the soil reservoir (organic carbon) is about $120 \mathrm{Gt}$ per year. Respiration of living organisms (including humans and their livestock) and oxidative combustion. Units of measurement Gt of carbon, fluxes - per year. The colors of the arrows correspond to the color of the carbon. * Deforestation is $\sim 2$ Gt C year-1. 14 As a result of a fire, a little less than $120 \mathrm{Gt}$ per year of reservoir carbon "plants and soil" is emitted into the atmosphere. The biosphere is considered a small carbon sink. Approximately $2 \mathrm{Gt}$ of carbon emissions from plants and soil are associated with deforestation. This contributes to increased carbon loss and reduced carbon uptake by plants and soil. Therefore, over time, the size of the carbon pool in plants and soil decreases. Coal / oil / gas tanks (which provide most of the industry's energy needs) are also being reduced by about $6 \mathrm{Gt}$ per year. If there is less carbon in the plant and soil reservoir, as well as in the coal / oil / gas reservoir, there should be more carbon in the atmosphere and ocean reservoirs. To date, humans have emitted about $300 \mathrm{Gt}$ of gray carbon, but more than 5,000 Gt remain in the lithosphere that could potentially be available for human use. It is estimated that about 2,000 Gt of carbon is currently found in terrestrial ecosystems (plant and soil reservoirs), with about 75 percent of this carbon being stored in natural forest ecosystems. However, about 50 percent of the world's forests have been deforested because current land-based carbon stocks are well below their natural carbon capacity. Carbon cycles between the lithosphere, hydrosphere, atmosphere and biosphere, but its residence time in each of these reservoirs varies considerably. The concentration of carbon in the atmosphere due to the release of carbon from the lithospheric reservoir will remain at a high level for a long time, even if gray carbon emissions are stopped immediately. Two ways of carbon transfer from the atmosphere are: 1) dissolution in river and ocean water and, ultimately, incorporation into carbonate rocks; and 2) carbon uptake by plants and storage in the biosphere. The currents of the terrestrial biosphere and atmosphere occur on a faster time scale and are more under human control than the currents of the hydrosphere. Addressing climate change will require both reducing gray carbon emissions and maximizing carbon uptake by the biosphere. A healthy biosphere provides buffering capacity for changes in the carbon cycle [11].

Various processes allow forests to survive in the face of changing environmental conditions, including climate change. Natural forests are characterized by rich biodiversity at all levels: genetic, taxonomic and ecosystem. This is especially evident when, in addition to the diversity of plants and vertebrates, we consider invertebrates, bacteria and fungi, as well as the vast network of ecological and related interactions that together make up a functioning ecosystem. Genetic diversity within species provides, among other things, the possibility of microevolution, through which populations can quickly adapt to local conditions. High taxonomic diversity provides a pool of species with different life cycles and resistance to niches, from which natural selection can identify the plant or animal most suitable for new conditions. Natural selection affecting the rich biodiversity of natural forests can also lead to the optimization of plant physiological processes and the optimization of trophic interactions in response to environmental changes. 


\section{Conclusions}

Natural forests play an important role in the global carbon cycle. Biomass and soil store about three times more carbon than the atmosphere currently contains, and the annual carbon exchange between the atmosphere and natural forests is 10 times the annual global carbon emissions from people burning fossil fuels. Although natural forests store such a significant amount of carbon, little attention has been paid to the role of forests in tackling climate change by policymakers to date. However, at the 2007 United Nations Climate Change Conference in Bali (UNFCCC 13), the international community recognized the need to reduce emissions from deforestation and forest degradation (REDD) as a vital component of a comprehensive solution to climate change. The importance of achieving REDD for climate change can be appreciated when one considers that about 35 percent of the greenhouse gases stored in the atmosphere are caused by deforestation in the past, and about 18 percent of annual global emissions are the result of ongoing deforestation (IPCC 2007) [13]. Moreover, even when the forest is not cleared to make way for other land uses, there are significant and ongoing carbon dioxide emissions from commercial logging and other land uses that reduce the carbon stored in the ecosystem. Consequently, there is now great interest and a truly urgent need for the development and application of methods to better determine the amount of carbon stored in natural forests and how these pools change as a result of human land use activities.

\section{Acknowledgments}

The work was carried out within the framework of the state assignment of the Ministry of Science and Higher Education of the Russian Federation (topic No. 075-03-2021-074 / 4).

\section{References}

1. A.I. Utkin, D.G. Zamolodchikov, O. V. Honest, Pools of phytomass carbon, biological carbon and soil nitrogen in the forest fund of Russia, 18 (2019)

2. A.M. Tarko, Anthropogenic changes in global biospheric processes. Mathematical modeling, 231 (2019)

3. R.A. Gakaev, Comprehensive assessment of the current state of the mountain-forest landscapes of the Chechen Republic and measures for their optimization, 189-194 (2008)

4. R.A. Gakaev, I.A. Bayrakov, M.I. Bagasheva, Environmental problems. Looking into the future, 50 (2020)

5. A.M. Vladimirov, F.A. Imanov, Principles for assessing the ecological flow of rivers, 225 (2019)

6. Ya.P. Molchanova, Hydrochemical indicators of the state of the environment, 192 (2019)

7. N.I. Egorova, O. I. Mityakova, Environmental Innovation and Sustainable Development, 209 (2020)

8. P.P. Tans, D.W.R. Wallace, Change and Pedogenic Carbonates, 257 (2018)

9. R.T. Watson, I.R. Nobel, Land Use, Land-use Change, and Forestry. Cambridge University Press, 236 (2018)

10. J. Meckling, L. Hughes, New Political Economy, 88 (2020)

11. K.A. Hibbard, S. Archer, D.S.Schimel, D.W. Valentine, Biogeochemical changes accompanying woody plant encroachment in a subtropical savanna. Ecology, 82 (2019) 
12. H.C. Monger, Soils as generators and sinks of inorganic carbon in geologic time, 27 (2020)

13. J. Meckling, L. Hughes, Protecting Solar: Global Supply Chains and Business Power. New Political Economy, 88 (2019)

14. I. Monasterolo, M. Raberto, Ecological Economics, 228 (2020) 